\title{
A Contribution for the Investigation of Natural Fires in Large Compartments
}

\author{
E. HAGEN and A. HAKSEVER
}

Institut für Baustoffe, Massivbau und Brandschutz

der Technischen Universität Braunschweig, FRG

\section{ABSTRACT}

To provide fundamental knowledge about fire development and fire spread in large fire compartments, a project "Natural Fire" is established in "Sonderforschungsbereich 148" at the Technical University of Braunschweig. The full scale fire experiments are carried out in a fire room with variable sizes between $500 \mathrm{~m}^{3}$ and $2000 \mathrm{~m}^{3}$, using the facilities of the Technical Research Centre of Finland. The first test series, which should determine the behaviour of the burning rate in dependence of the ventilation-conditions and the fire-load-configurations, is presented and the experimental results are discussed in this contribution.

\section{INTRODUCTION}

The research project "Natural Fires"

The fire resistance of structural elements is usually determined by means of fire-tests with respect to ISO-Fire Curve $/ 1 /$. In this procedure, the structural element which is being tested is subjected to a certain fire exposure under defined structural boundary conditions. In practice, however, in a natural firecase, the structural elements are heated with respect to totally different non steady temperature conditions. In order to determine the structural response of bearing members in such a fire case, it is essential to predict at first the development of natural fire taking into account the parameters which have an influence on fire.

Being aware of the importance of the natural fires a new research project in Sonderforschungsbereich 148 - special research group for fire problems - was established at the Technical University of Braunschweig four years ago to investigate the phenomenon of natural fires both theoretically and experimentally. The new project has the goal to research the development of fires not only in the preflashover phase but also the fully developed and the cooling down phases for significant boundary conditions. Besides that the investigations intend to provide necessary information also for the non steady heat transfer conditions, thus a structural fire engineering design can be done as realisticaliy as possible. 
Figure 1 shows the most important parameters which have a main influence on the development of a natural fire. Especially the fire load, the ventilation conditions and the fire room itself are the essential parameters influencing the development of natural fires. The amount of fire loads as well as their configuration in a fire room, the size and the place of openings, the size of fire room and the physical properties of walls, ceiling and floor are the ma in parameters which deserve a careful investigation. Bound to these parameters some certain physical magnitudes are to determine especially concerning the burning rate and the fire spread rate, the temperature fields, the components of the hot gases and the heat and mass flow conditions in the fire room.

The research project analyses the interaction between the parameters given in figure 1 mainly in an experimental way. The experimental program of the project chiefly includes full-scale tests. The reason for this decision is that many theoretical calculations use at present time the results of sma11-scale tests on empirical basis, especially the burning rates of the combustibles used in the models are obtained by means of tests carried out in a furnace with dimendions less than $2.0^{3} \mathrm{~m}^{3}$. Calculations based on such empirical data do not provide satisfactory results for natural fires in practice, which in fact has been proved in Braunschweig with the analys is of small and full-scale fire tests $/ 2 /$.

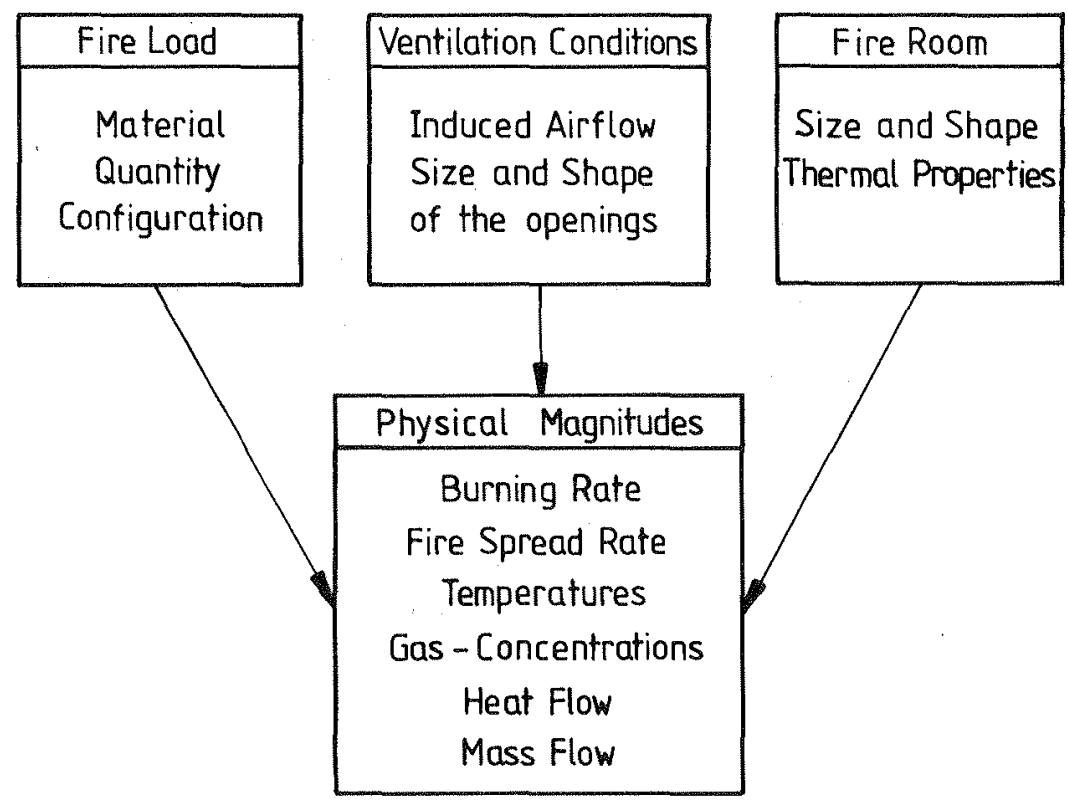

Fig. 1: Parameters influencing the development of natural fires and the physical magnitudes to be measured 


\section{General Scope}

In order to carry out the experimental program on the basis of full-scale fire tests the facilities of the Technical Research Centre of Finland are being used where a fire room is available with a variable size between $500 \mathrm{~m}^{3}$ and $2000 \mathrm{~m}^{3}$. Within the scope of a carefully planned research program of the next three years, the development of the natural fires in large compartments will be investigated.

The fire loads mainly consist of pine wood in form of sticks with dimensions of $4 \times 4 \times 80 \mathrm{~cm}^{3}$. The sticks are nailed together to cribs, the ratio between wood and air inside the cribs amounts to $50 \%$.

The first goal of the research program is to clear the influence of ventilation conditions and distribution of fire load on the fire development. Small-scale tests carried out in Braunschweig $/ 2 /$ have shown that a very distinct interation exists between these two parameters during the fire: The ventilation conditions and the distribution of the fire load in connection with their density and physical properties determine the amount of oxygen which can participate in the burning process. For this reason the density, the distribution and the physical properties of the fire loads must be considered together with air flow conditions. Consequently experimental work planned has the intention to define a reasonable ventilation parameter taking into account these interaction processes in large fire rooms. Especially a relationship between natural ventilation and artificial ventilation conditions must be provided for large compartments.

\section{Determination of the burning rate}

The burning rate is the most important physical parameter which should be determined carefuliy in the experimental tests. In order to predict the development of fire by means of a heat balance calculation as realistically as possible it is essential to know the burning rates in the ignition phase, during the fully developed fire and in the cooling down period of fire. For this reason, the prediction of the burning rate of the combustibles due to different fire influencing parameters gains a special attention for theoretical investigations.

Determination of the burning rate by means of the oxygen consumption. In the tests, two ma in possibilities are used to determine the burning rates of the wood cribs. First the unburned fire load was weighed by the help of a weighing platform during the fire. The derivation of the measured curve of the rest fire load against the time consequently provides the burning rates. However by means of this procedure information about the burning rates can only be obtained for a local area bound to size and shape of the weighing stage during a certa in time of fire duration. Information about the total burning rate, especially in a large compartment can not be available.

In order to obtain a ful1 information about the burning rates, the method of analyzing the exhaust gases $/ 3,4 /$ is preferred in the tests. This method however implies to know as exactly as possible the amount of consumed oxygen per time unit. The procedure which is also used in the tests is explained in figure 2. 


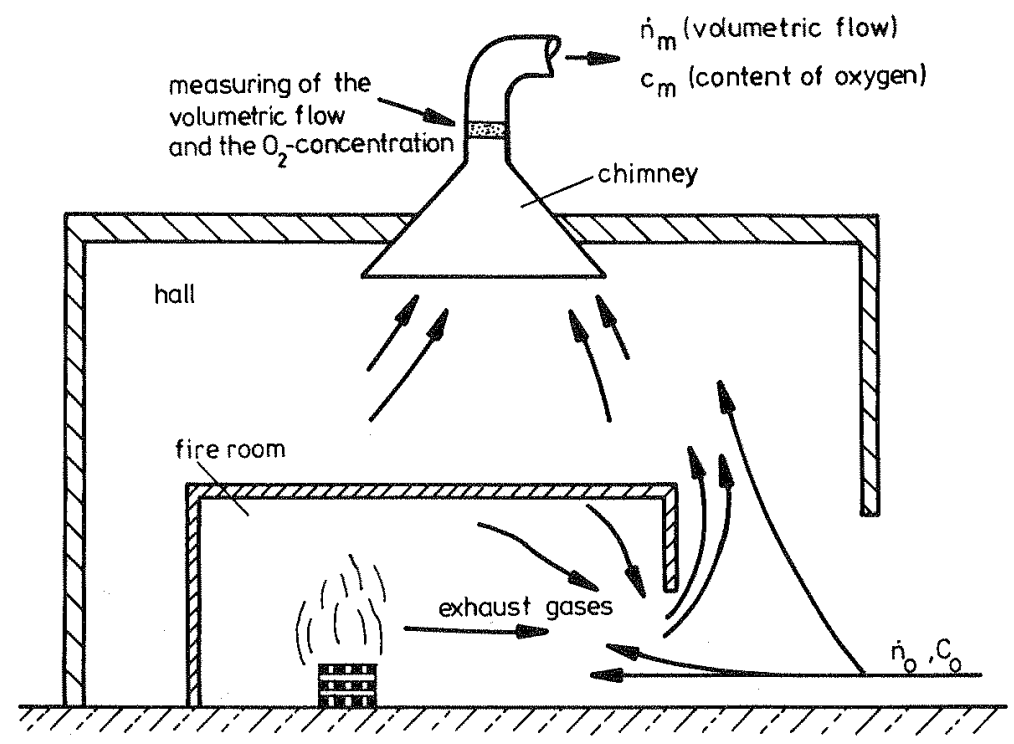

Fig. 2: Determination of the burning rate by means of hot gas analys is

Figure 2 illustrates the cross section of a fire room (the hatched painted wa11) inside a hall building. In the chimney, on top of this building, a suction fan is installed which can produce under pressure inside the hal1. Therefore all the gases going out of the hall pass through the chimney.

As measuring the volumetric flow $\dot{n}_{m_{i}}$ and the content of oxygen $c_{m_{t}}$ of the gases passing through the suction plant, ${ }$ it is possible to obta in the $m_{\text {total }}$ energy released in the building. The total air flow in the plant, $n_{m}$ consists of the incoming fresh air flow $\dot{n}_{0}$ with an oxygen concentration $c_{0}=20.8 \%$ and of the exhaust gases produced by the fire. Under the assumption that all the combustion gases are sucted into the duct, the knowledge of the measured values $\dot{n}_{m}$ and $c_{m}$ enables to determine the rate of heat release and consequentiy the total bur- ${ }^{m}$ ning rate of the fire loads in the fire room. The mathematical expression of this process is given by eq (1).

$\dot{R}=\frac{1}{H_{u}} \frac{d Q}{d V_{02}} n_{02}$

$H_{4}$ is the lower calorific value of wood and the quotient $d Q / d V_{02}$ represents the efergy released with respect to volumetric unit of the oxygen consumed during the combustion. $\dot{n}_{02}$ is the amount of oxygen consumed as given by Eq.(2)

$n_{02}=n_{0} c_{0}-n_{m} c_{m}$

However the amount of fresh air flow in the hall building cannot be measured. Therefore an additional relationship must be derived for the combustion reaction of cellulose as given in $\mathrm{Eq} .(3)$.

$\mathrm{C}_{6} \mathrm{H}_{10} \mathrm{O}_{5}+6 \mathrm{O}_{2} \rightarrow 6 \mathrm{CO}_{2}+5 \mathrm{H}_{2} \mathrm{O}$ 
The eq. (3) shows that the total number of molecules produced during the combustion is 11 when 6 oxygen molecules are consumed. Consequently the alternation in the total gas flow inside the hall building can be written as in eq.(4)

$\dot{n}_{m}-n_{0}=\frac{5}{6} n_{02}$

The eq. (4) combined with eq.(2) results into eq. (5) which provides the rate of oxygen consumption.

$n_{02}=n_{m} \frac{c_{0}-c_{m}}{1+5 / 6 c_{0}}$

The eq. (5) indicates that the air flow $n_{m}$ and the axygen concentration $c_{m}$ are the necessary parameters alone to be measured in order to determine the rate of oxygen consumption during the fire and the eq.(1) can be used for the analys is of burning rates.

Comparison of the burning rates obtained by means of weighed rest fire load and the hot gas analysis. Figure 3 shows the burning rates of a test obtained by means of the hot gas analys is and also by means of weighing the rest fire loads on a stage during the fire. In this test, all the wood cribs were loaded up on the stage.

In figure 3 , the full line belongs to the measurements of weight loss while the dotted line presents the results from the hot gas analysis. The results from the hot gas analysis show a certain delay with respect to the results of weight loss measurements for the hot gases need a certain time to reach the suction plant and to activate the measuring devices. However it is interesting to observe that both of the curves show a relatively good agreement and consequently that the analysis of hot gases can provide reliable results.

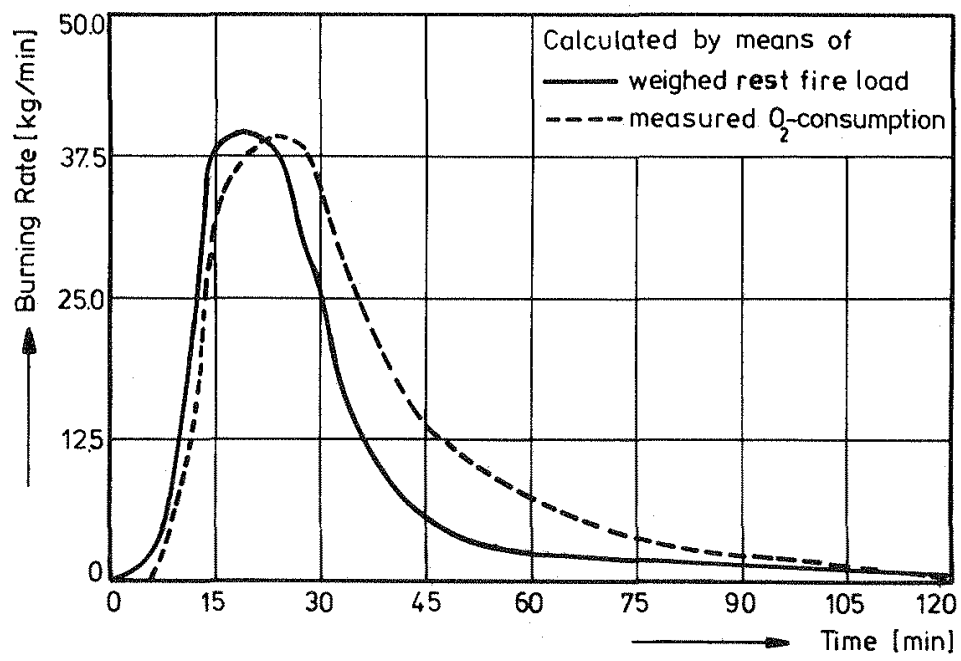

Fig. 3: Burning rates obtained by measuring the rest fire loads and the oxygen consumption 
Experiments carried out by variation of ventilation and fire load conditions Presentation of experimental analysis. The research program has included 5 full-scale tests in 1983 in order to investigate the influence of the natural ventilation conditions and of the distribution of the fire load on the development of real fires. The test fire room was made out of aerated concrete and has the internal dimensions of $14.4 \mathrm{~m} \times 7.2 \mathrm{~m} \times 3.5 \mathrm{~m}$. As ventilation conditions, three different sizes and shapes of openings in the walls of the test room were foreseen. Figure 4 gives necessary information about the tests with interesting boundary conditions.

In the first test, a window opening with dimensions $5.25 \mathrm{~m} \times 1.2 \mathrm{~m}$ in the front wall was used, while in the second and the third tests a door opening was constructed at the same place. Another window opening with dimensions $10.5 \mathrm{~m} \times$ $1.2 \mathrm{~m}$ and with a mean support was arranged at the long side of the fire room for the 4 . and 5 . tests. Figure 4 gives additional informations about the distribution of fire loads and also about the ventilation factors which result from the product of the opening area and the square root of the height of the opening.

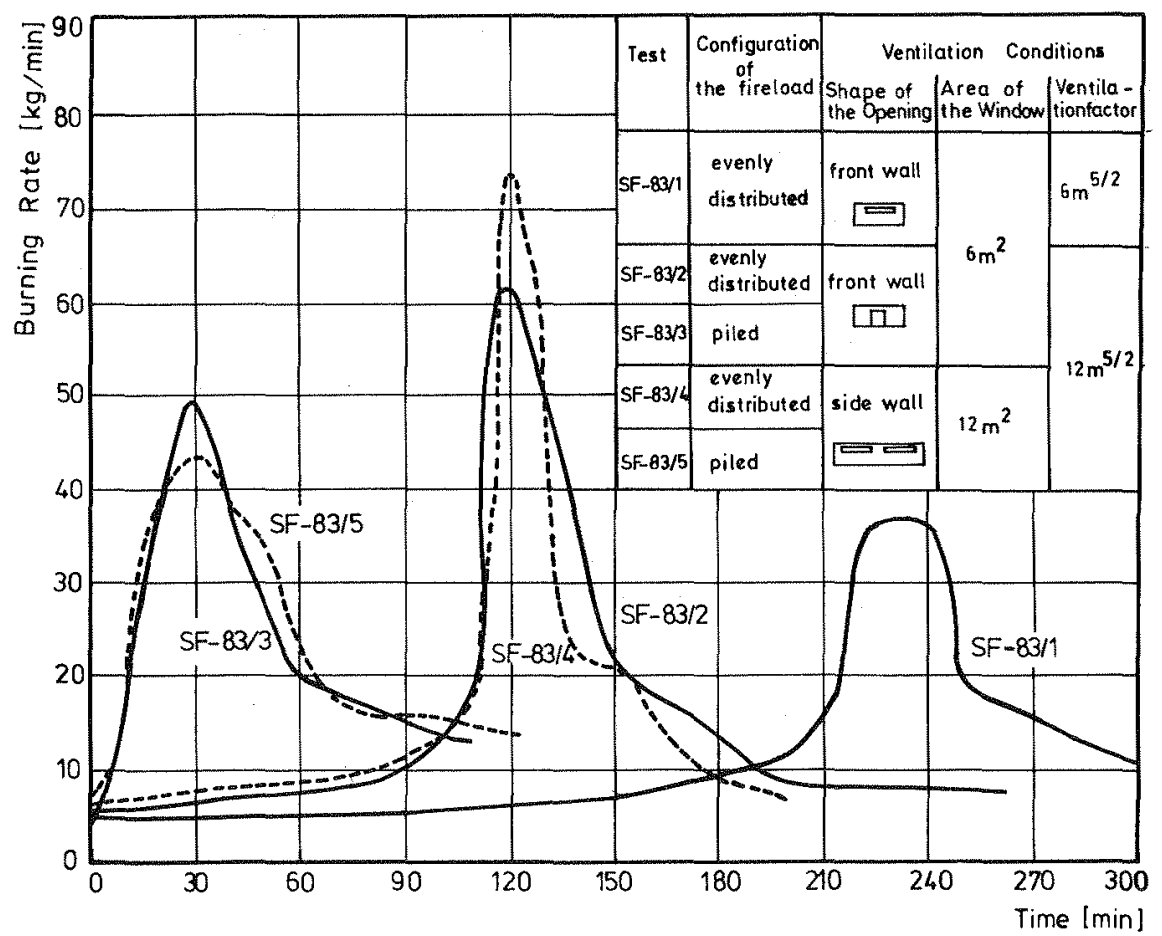

Fig. 4.: Burning rates of the full-scale tests and general information concerning the tests

Sma11-scale tests carried out in Japan and Sweden have shown that the maximum possible burning rates of wood cribs are linearly bound to the ventilation factor for ventilation controlled fires $/ 5,6 /$. Theoretical investigations with mass and heat balance calculations for this purpose also confirm the test results $/ 7 \%$. In order to find out whether such a relationship is also valid for large compartments and in order to gain certainty if the ventilation factor 
alone dominates the burning rates, tests have been carried out first with different ventilation factors but with the same size of openings. In the further step, the ventilation factor was kept fix by different opening areas. The fire loads consisted of $2000 \mathrm{~kg}$ of wood cribs in all tests have been either evenly distributed or concentrated on the middle area of the fire room.

Burning rates of the experiments. The burning rates of the mentioned full-scale tests are obtained by means of the hot gas analysis, the result is illustrated in figure 4 . The tests represented by full lines had the openings of $6 \mathrm{~m}^{2}$ at the front side, whereas the dotted lines represent the results of two tests with openings at the long side of the fire room.

The first two curves (SF-83/5, SF-83/3) with a maximum at the 30 th minute belong to the fire tests where the fire loads were concentrated in the middle of the floor. The curves SF-83/1 and SF-83/2, plotted with full lines show the calculation results from the tests which were carried out with the same size of the openings but different ventilation factors. On the contrary, the curves SF-83/2 and SF-83/4 belong to the tests with fix ventilation factor but the areas of the openings differ by factor two.

Conclusions drawn on burning rates of the tests. The following conclusions from fig. 5 can be drawn:

1. In case of evenly distributed fire loads the maximum values of the burning rates as well as the concerning times are influenced very distinctly by the ventilation factor as the comparison of the curves SF-83/1 and SF-83/2 proves this assertion. It can be stated that the maximum burning rates and the concerning times are proportionally influenced by the ventilation factor.

2. The maximum value of the burning rates by evenly distributed fire loads is dependent not only on the ventilation factor but also on the shape and size of the openings. This important result can clearly be seen by the pair of the curves $S F-83 / 2$ and $S F-83 / 4$. The curves show different maximums in the case of same ventilation factor with different sizes of openings. With increasing the size of the openings the burning rates have also an increasing tendency although the same ventilation factor is used. So it can be concluded that the maximum value of the burning rates of natural fires in large compartments is not on $7 y$ limited by the ventilation factor.

3. The maximum value of the burning rates and the concerning time are effectively influenced by the configurations of the fire loads as the comparison of the curves SF-83/2 and SF-83/3 shows clearly. In case of eventy distributed fire loads, the occurance of the maximum value of the burning rates is shifted to later fire durations due to lower fire spread rates especially at the beginning. The maximum burning rate is in this case obviously higher than in the case of concentrated fire loads on the middle part of the floor area. This can be explained by the fact that only a part of the fresh air coming through the opening penetrates the pile of wooden cribs and participates in the combustion, for the total surface of the fire load is relative small.

Therefore the burning rate of the concentrated fire load is limited due to two reasons: The first reason is the size of the opening of the enclosure and the second reason is the small surface of the fire load. Due to this limitation by the surface of the fire load the tests with concentrated fire loads do not show increasing burning rates with increasing sizes of the opening when the ventilation factor remains constant (see curves SF-83/3 and SF-83/5).

The burning rate of the wood cribs has proved in tests to be a function of the ventilation factor and, besides that of the size of the openings and of the effective surface of the fire loads. That means, that the ventilation factor and the surface of the fire loads influence both the maximum value of the burning 
rate and the fire spread rate in case of evenly distributed fire loads and as well as of concentrated fire loads. However in case of evenly distributed fire loads the size of the openings has an influence only in the maximum of the burning rate, whilst the fire spread rate remains uninfluenced (SF-83/2, SF-83/4).

\section{THEORETICAL INVESTIGATIONS}

Application of the heat balance calculations

Since 1976 the "Bundesministerium für Raumordnung, Bauwesen und Städtebau (Ministry of urban affairs)" has supported a research program concerning the development and spread of fires in small and large rooms. Within the activities of this research work calculation models have been developed to analyse the fires theoretically, however the reliability of the models has first been proved more effectively by means of the experimental investigation of the new project "Natural Fires" in Sonderforschungsbereich 148.

Introduction of the heat balance program used

The heat balance program uses the following basic assumptions for the calculations /7/:

- The fire room with only vertical openings has a homogeneous temperature distribution.

- On the surfaces of the walls, the ceiling and the floor the heat transfer occurs with respect to one dimensional conditions and vertical to the heated surface.

- There is a so-called neutral plane existing inside the fire room which provides a pressure balance on its level. Ebove this plane, overpressure and below it underpressure exists in the fire room.

With the help of these assumptions relationships for the energy- and mass balances were developed /7/. Results of the calculations are the temperature and mass-flow which can be obtained by the solution of nonlinear equations by means of an appropriate iteration procedure. Thus it is possible to calculate the temperature-time development in any large compartment on the basis of the results of experiments with the knowledge of the burning-rate time function derived from the tests.

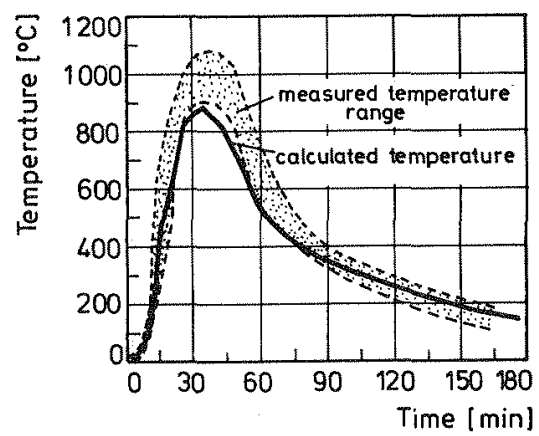

Fig. 5: Measured and calculated hot gas temperatured of test SF-83/3 (see fig.4) 
Figure 5 shows the temperature-time curve measured by the test "SF-83/3" (see fig. 4) together with the results of the heat balance calculation. The dotted area indicates the temperature distribution measured at different leveis inside the fire room. The calculation takes into account besides the special thermodynamical boundary conditions oxygen consumption in order to determine the burning-rate-time function.

Figure 5 illustrates that measured and calculated temperatures show a satisfactory agreement even during the cooling down period of the fire. However the calculated temperatures during the fully developed fire period are apparently low. The reason for this notice are some smal1 inaccuracies in the measuring of oxygen consumption and as well as the assumption of evenly distributed temperatures in the heat balance model, which has generally not the validity for large fire rooms. In fact the inhomogenity in the temperature distribution is proved by fig. 6 for it illustrates different temperatures respectively in five different heights inside the fire room. Temperatures between the highest $(25 \mathrm{~cm}$ below the ceiling) and lowest measuring points differ more than $200 \mathrm{~K}$ as it can be seen in figure 6.

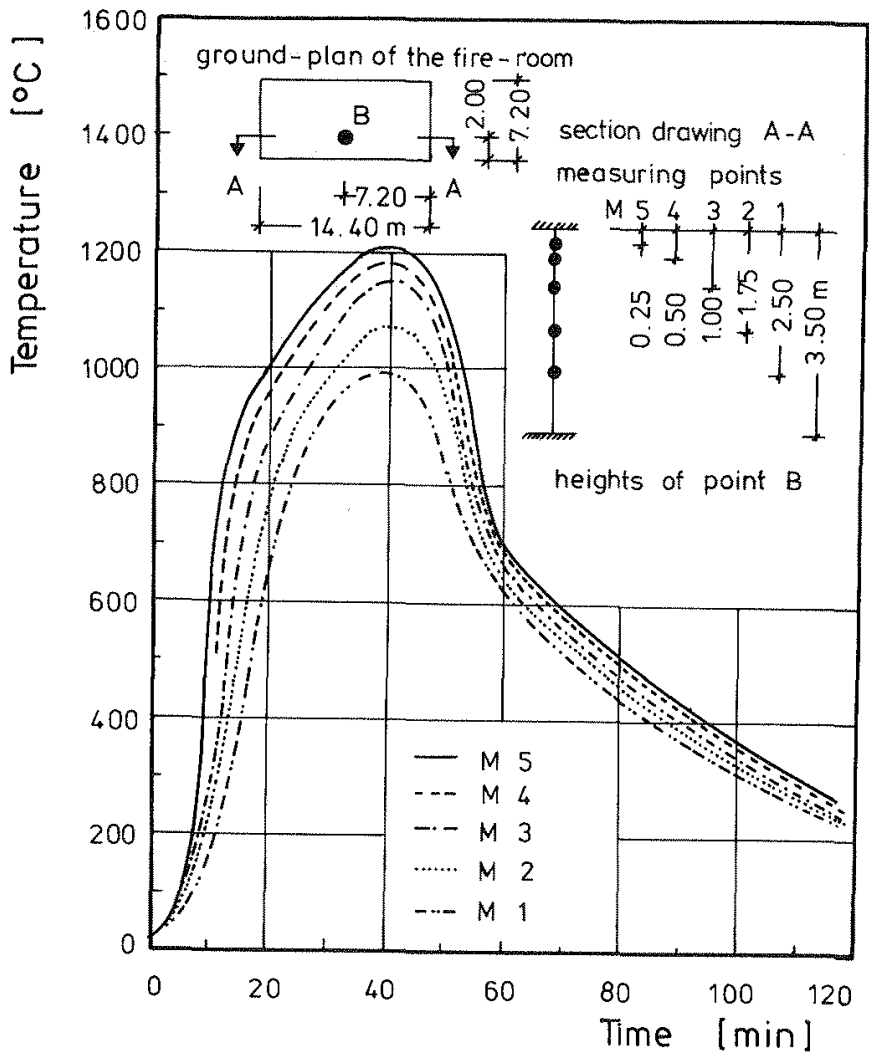

Fig. 6: Development of hot gas temperatures in different levels of test SF-83/3 (see fig. 4) 
Experimental investigations have been conducted to derive the following conclusions concerning the burning rates of the fire loads as wood cribs in large compartments :

The burning rate depends on the ventilation factor $A \sqrt{H}$, the window area and the fire load configuration or the surface area of the fire load (not speaking about the mass dependence and the dependence of the geometry of the enclosure). The ventilation factor has an effect on the maximum value of the burning rate and on the velocity of the extension of the flames. Comparing experiments with the same factor $A \sqrt{ }$ h but different window areas one can see that the window area shows an additional effect on the maximum burning rate.

\section{REFERENCES}

1. DIN 4102, "Baulicher Brandschutz", Teil 2, 1977

2. Hagen, E.: Experimentelle Untersuchungen über die einen Brandablauf bestimmenden Parameter. 3. OffentTiches Forschungskolloqui um des Sonderforschungsbereichs 148 "Brandverhalten von Bauteilen", Karlsruhe, 1982

3. Ahonen, A., Kokkola, M.: Measurements of the Rate of Heat Release in Room Fires. Technical REsearch Centre of Finland, Res. Note 72 1982 (Espoo, 1982)

4. Babrauskas, V.: Rate of Heat Release Apparatur using Polymethylmethacrylate and Gaseous Fuels. Fire Safety Journat 5, 1982

5. Kawagoe, K.: Fire Behaviour in Rooms. Building Research Institute, Report Nr. 27, Tokyo, 1958

6. Nilsson, L.: Time Curve of Heat Release for Compartment Fires with Fuel of Wooden cribs. Lund Institute of TEchnology, 1974

7. Schneider, U., Haksever, A.: Wärmebilanzrechnungen für Brandräume mit unterschiedlichen Randbedingungen, Heft 46 der Schriftenreihe des Instituts für Baustoffe, Massivbau und Brandschutz der Technischen Universität Braunschweig. 